\title{
Dueños y poseedores de la naturaleza: la relación artificial-natural en la Dióptrica de Descartes
}

\section{Owners and possessors of nature: The relation artificial-natural in Descartes's Dioptrics}

\author{
SERGIO GARCÍA RODRÍGUEZ \\ Universitat de les Illes Balears
}

Recibido: 09/08/15 Aceptado: 10/08/15

\begin{abstract}
RESUMEN
La interpretación actual de la ciencia cartesiana ya no concibe ésta como una mera deducción desde los principios metafísicos, sino que reivindica el papel de la experiencia en ella. El presente artículo tratará de dar un paso más, defendiendo que existe una dimensión instrumental en la ciencia cartesiana. Para ello, se analizará la modificación que Descartes realiza en la Dióptrica de la relación artificial-natural y que posibilita una lectura instrumentalista.
\end{abstract}

PALABRAS CLAVE

DESCARTES, ARTIFICIAL, NATURAL, INSTRUMENTALISMO, CIENCIA

\section{ABSTRACT}

The current interpretation of the Cartesian science no longer sees it as a mere deduction from the metaphysical principles, but claims the role of experience in it. This paper will try to go one step further, arguing that there is an instrumental dimension in the Cartesian science. With this purpose in mind, we will analyze the modification performed by Descartes in the Dioptrics regarding the artifitial-natural relation, which enables this instrumentalist reading.

KEYWORDS

DESCARTES, ARTIFICIAL, NATURAL, INSTRUMENTALISM, SCIENCE

(C) Contrastes. Revista Internacional de Filosofia, vol. XXI-N²2 (2016), pp. 75-90. ISSN: 1136-4076

Departamento de Filosofía, Universidad de Málaga, Facultad de Filosofía y Letras Campus de Teatinos, E-29071 Málaga (España) 


\section{INTRODUCCIÓN:}

LA COMPRENSIÓN DEL PAPEL DE LA CIENCIA EN EL PROYECTO CARTESIANO

La Figura de Descartes como un FiLÓSOFo Racionalista que abjura de la experiencia tratando así de obtener unos fundamentos últimos e indubitables en forma de certezas metafísicas, en suma, lo que Williams (1978) describirá bajo la imagen del «investigador puro», encarna la visión de Descartes que nos resulta más familiar. Contra esta lectura, intérpretes como Clarke (1982) o Garber (1992), han puesto de manifiesto la importancia que la experiencia juega en el proyecto cartesiano, revalorizando así el papel de ésta tanto en su propuesta científica como en la filosófica - pues hasta entonces había pervivido la interpretación de la ciencia cartesiana como una mera derivación extraída de sus principios metafísicos-, transformando la figura Descartes en la de un «científico que filosofa». Siguiendo esta lectura, mi intención es dar un paso más, sosteniendo que Descartes no es un científico únicamente por su consideración hacia la experiencia sino que, siguiendo a otros científicos de su época como Francis Bacon, él es un científico por su comprensión de la ciencia como proceder mediante el que podemos obtener «consecuencias útiles», esto es, frutos como los del árbol de la sabiduría que Descartes señala en los Principios de la filosofía.

Un correcto análisis de la ciencia cartesiana exige la consideración de los tratados científicos - como la Dióptrica - repudiando una comprensión de su proyecto científico fundada exclusivamente en sus escritos filosóficos, pues dichos tratados ejemplifican la forma en que Descartes concibe la ciencia. El ejemplo que encarna la Dióptrica ha gozado de consideración en base a la enunciación cartesiana de la ley de refracción, cuya formulación en términos matemáticos posibilita a Descartes, tras siglos de intentos fracasados en óptica, calcular el efecto de la refracción. Ahora bien, a pesar de que sea en la Dióptrica donde se exponga dicha ley, no se debe olvidar que el tratado está orientado hacia otro objetivo, para el cual la formulación de la ley de refracción se trata de un paso más hacia la consecución del mismo: la construcción de las lentes más perfectas.

El presente artículo situará tal objetivo en el centro del análisis, tratando de evidenciar la existencia de una continuidad entre el Discurso del método y la Dióptrica, donde esta última encarna un ejemplo de cómo hacernos «dueños y poseedores de la naturaleza», a fin de mostrar la dimensión instrumental que caracteriza a la ciencia cartesiana. Con este fin, se realizará un análisis de la distinción entre «órganos naturales» y «órganos artificiales» que Descartes expone en la Dióptrica y sobre la que se posibilita evidenciar dicho instrumentalismo. La distinción entre natural y artificial da un vuelco a raíz del enfoque cartesiano, invirtiendo la concepción aristotélica — caracterizada por 
una interpretación de lo artificial ontológicamente defectiva- y postulando en consecuencia que los órganos naturales, vinculados a nuestra corporalidad, son insuficientes para permitir el conocimiento del mundo. De este modo, es necesaria una corrección por parte de los órganos artificiales para suplir tales deficiencias. Por tanto, el análisis del papel ejercido por los órganos artificiales sobre los órganos naturales posibilitará elucidar la dimensión instrumental que posee la ciencia cartesiana, en tanto que, se dirige a perfeccionar nuestro conocimiento - y así nuestro dominio - de la naturaleza.

\section{Descartes y EL SUJETO ACTIVO RENACENTISTA}

En el siglo XVII florece ya de forma clara la primera revolución científica, cuyo desarrollo está amparado por el triunfo de la cosmovisión renacentista del sujeto que, en la línea antropocéntrica propia del Renacimiento, habrá «[...] dejado definitivamente de ser el piadoso espectador de las maravillas de la creación divina para convertirse en un elemento activo y operante que intenta hacer suyo el poder existente en los órdenes divino y natural»». ${ }^{1} \mathrm{El}$ sujeto renacentista está preocupado por la acción, busca la intervención en el mundo como forma de alterar el orden de la naturaleza para ponerlo a su servicio e intereses, siendo el auge de la magia renacentista un reflejo de esa actitud. ${ }^{2}$

Bajo este contexto se constituye en 1604 el colegio jesuita de La Flèche en el que Descartes se educó, cuyo programa académico, basado en la Ratio Studiorum, distaba mucho de corresponderse con una formación tradicional al estilo de las universidades medievales. El programa jesuita, siguiendo una línea renacentista, ponía un énfasis muy claro en el papel práctico que jugaban las matemáticas ${ }^{3}$ —encaminado hacia su utilidad en ámbitos como la mecánica. El colegio se caracterizó, asimismo, por una amplia libertad educativa que permitió a los profesores tratar autores renacentistas - aun cuando fuera solo con objetivos críticos. A todo esto cabe añadir que los conocimientos de la filosofía renacentista que Descartes pudo adquirir de su educación no se redujeron solo al contacto mantenido en el colegio, sino que se complementaron con la lectura autónoma de «[...] cuantos libros pudieron caer en mis manos referentes a las ciencias que se consideran como las más curiosas y raras ${ }^{4}$,

1 Yates, 1983, p.172.

2 La influencia de la magia renacentista en el desarrollo de la ciencia y la técnica ha sido señalada por autores como Mumford, quien sostiene que «[...] la magia dirigió la mente de los hombres hacia el mundo externo: sugirió la necesidad de manipularlo. Ayudó a crear los instrumentos para conseguirlo, y afinó la observación en cuanto a sus resultados» (Mumford , 1979, p.55).

3 Cf. F. Dainville, 1954, pp. 6-21 y 109-23.

4 Las referencias se realizarán a través de la edición de Charles \& Adam Tannery (AT). Sin embargo, las citas se basarán en las traducciones de distintas obras de Descartes en castellano expuestas en la bibliografía. En el caso de la Dióptrica, la traducción utilizada será la de Quintás, 
indicando, en la línea de intérpretes como Turró o Yates, una posible influencia del pensamiento mágico renacentista que puede observarse en las Cogitationes Privatae así como en su correspondencia de 1618 con Beeckman. La educación de Descartes, en suma, lejos de ejemplificar una formación típicamente medieval, se caracterizó por un conocimiento, tanto de la tradición como de lo contemporáneo, encaminado hacia unos intereses prácticos donde la curiosidad por la magia se transformará progresivamente en un desencanto por ésta y un creciente interés en la ciencia que quedará evidenciado en el Discurso del método, donde se expondrá el papel que Descartes otorga al conocimiento y, concretamente, al conocimiento científico.

Siguiendo la línea interpretativa sostenida por Clarke y Garber, Descartes es un científico que filosofa cuya contribución será decisiva para la constitución definitiva de la «nueva ciencia». La aportación cartesiana a la nueva ciencia se ha circunscrito fundamentalmente a un abandono definitivo del interés aristotélico por las cualidades, centrándose, en consecuencia, en aspectos cuantitativos - extensión, fuerza y movimiento. Con vistas a la cuantificación de la realidad que Descartes representa, se concluye que el aspecto más fundamental de su propuesta científica es su mecanicismo, concebido únicamente como una geometrización de los fenómenos susceptible de ser cuantificada. Ahora bien, a pesar de que las matemáticas jueguen un papel fundamental en varios aspectos de la ciencia cartesiana, reducir ésta a un simple tratamiento cuantitativo de los fenómenos elude otro de los elementos fundamentales sobre los que se constituye la propuesta científica cartesiana: la preocupación por la obtención de resultados útiles.

El cambio hacia una comprensión activa del papel del sujeto en el mundo - y su influencia en la educación de Descartes- puede considerarse el germen del instrumentalismo al que se dirige la ciencia cartesiana. El sujeto cartesiano no es un yo puro de connotaciones solipsistas, su interés último, siguiendo el símil del árbol de la ciencia, es la obtención de unos frutos con los que mejorar la vida. Este aspecto central de su propuesta científica quedará evidenciado de forma más contundente en el Discurso del método, preludio a una serie de tratados científicos que conforman la aportación más clara de Descartes a la ciencia.

Es en el Discurso donde Descartes manifiesta de forma más clara que el objetivo hacia el que se encamina su propuesta científica es a hacernos «[...] como dueños y poseedores de la naturaleza $\rangle^{5}$ para así obtener los frutos del árbol de la ciencia. La ciencia es una forma efectiva de ejercer el control sobre

mientras que en el caso del resto de obras se utilizará la traducción de Flórez. DESCARTES, Discurso del método, AT, VI, p.5.

5 Ibid., p.62.

Contrastes vol. XXI-N² (2016) 
los fenómenos, para la cual las matemáticas encarnan un papel instrumental donde la geometrización del mundo posibilita conocer «[...] la fuerza y las acciones del fuego, del agua, del aire, de los astros, de los cielos y de todos los cuerpos que nos rodean» ${ }^{6}$. En una línea baconiana, el conocimiento científico va ligado al dominio y a la intervención en la naturaleza con vistas a la obtención de consecuencias útiles con las que mejorar la vida de las personas:

[...] como dueños y poseedores de la naturaleza. Lo cual es muy de desear, no sólo por la invención de una infinidad de artificios que nos permitirían gozar sin ningún trabajo de los frutos de la tierra y de todas las comodidades que hay en ella, sino también principalmente por la conservación de la salud. ${ }^{7}$

Como Ribe ${ }^{8}$ ha evidenciado, la Dióptrica expondrá de forma clara las vinculaciones pragmatistas a las que la ciencia cartesiana apunta. A pesar de que la lectura más usual —A. M. Smith (1987), Wolf-Devine (1993)— de la Dióptrica se haya centrado en aspectos como la teoría de la percepción empleada por Descartes o su formulación de la ley de refracción —que apela a un carácter puramente cuantitativo del fenómeno de la luz, siguiendo así la línea interpretativa de la ciencia cartesiana que pone el acento en la matematización de la realidad-, realmente no debe olvidarse que el interés central de Descartes es construir las lentes más perfectas, ${ }^{9}$ así como perfeccionar las lentes que ya en su época se utilizaban. Esto nos enmarca en la interpretación de un Descartes

6 Ibid., p.62.

7 Ibid., p.62.

8 La tesis de Ribe, en la que me enmarcaré, entiende la Dióptrica como el reflejo de las aspiraciones baconianas de Descartes. En su artículo analiza en qué forma el tratado se vincula a consideraciones de tipo instrumental vinculadas a la obtención de frutos: Cf. N. Ribe, 1997, pp.42-61.

9 Se ha tendido a realizar lecturas de la Dióptrica poniendo el énfasis en aspectos como la ley de refracción, o la explicación fisiológica dada por Descartes sobre la percepción, ahora bien, estas explicaciones científicas son en el fondo meras herramientas con las que alcanzar el objetivo real de la Dióptrica que es la construcción de las lentes más perfectas, pues, tal y como ha señalado Vaccari, «The mastery of nature requires a previous step: its representation» (Vaccari, 2008, p.303). De hecho el mismo Descartes confirmará este papel instrumental que poseen esos elementos teóricos: «Así mismo considero que la ejecución de cuanto exponga [referente a la construcción de las lentes] debe depender de la habilidad de los artesanos que, generalmente carecen de estudios. Por esta razón, intentaré hacerme inteligible a todo el mundo y no omitir ni suponer nada que deba ser enseñado por otras ciencias. Esta es la razón por la que comenzaré refiriéndome a la explicación de la luz y de sus rayos; a continuación, habiendo realizado una breve descripción de las partes del ojo, detallaré la forma en que se realiza la visión. Finalmente [...] indicaré cómo las lentes pueden ser utilizadas con tal fin en virtud de las invenciones que pienso describir» (Descartes, Dióptrica, AT, VI, pp.82-3). 
para el que la ciencia es importante porque ofrece resultados, encaminándose la Dióptrica hacia la obtención de unos instrumentos que posibilitarán tal fin:

Mediante La Dióptrica tuve el deseo de mostrar que se podía avanzar lo suficiente en Filosofía como para acceder mediante la misma hasta el conocimiento de las artes que son útiles para la vida, ya que la invención de las lentes que aproximan los objetos, allí explicadas, son una de las más difíciles que jamás hayan sido indagadas. ${ }^{10}$

En suma, dicha valoración alternativa sobre el papel de la ciencia cartesiana en un sentido más instrumental parece confirmar la adhesión de Descartes a la cosmovisión renacentista de un sujeto activo que ante la naturaleza busca la intervención para la obtención de consecuencias útiles. La pertenencia de Descartes a esta cosmovisión, que en última instancia desvela uno de los elementos propios de la «nueva ciencia»: la consecución de resultados, deberá manifestar un cambio en la relación entre lo artificial y lo natural para poder extender el dominio sobre la naturaleza.

\section{DESCARTES CONTRA LA CONCEPCIÓN ARISTOTÉLICA DE LO ARTEFACTUAL}

Como se ha mostrado en el apartado anterior, el contexto renacentista en el que Descartes se educa posibilita una heterogeneidad filosófica donde, sin embargo, el aristotelismo continúaconstituyendo el paradigma filosófico vigente. De esta forma, todo intento por ofrecer propuestas alternativas implicó un enfrentamiento con la escolástica de corte aristotélico, dado que era precisa una crítica de las tesis vigentes como paso previo. Así, un análisis de lo artificial y lo natural en Descartes supone desafiar y negar determinadas tesis aristotélicas que pudieran representar un obstáculo para su filosofía. Aristóteles expone sus tesis principales de la relación artificial-natural fundamentalmente en el segundo libro de la Física. Allí, el papel del artefacto vinculado a la naturaleza es concebido en un doble sentido: o bien, como un elemento que complementa a la naturaleza y contribuye a su realización, o bien, como una forma de imitación (mímesis) de ésta:

En general, en algunos casos el arte completa lo que la naturaleza no puede llevar a término, en otros imita a la naturaleza. ${ }^{11}$

Si el papel de lo artefactual se concibe en términos miméticos, lo natural se entiende en el aristotelismo bajo la tesis de que «[...] los productos de la 
naturaleza están constituidos del mejor modo posible» ${ }^{12}$ conforme a la causalidad final. De esta forma, el artefacto actúa como un reflejo de lo natural, que representa el arquetipo de cómo las cosas se deben hacer. ${ }^{13} \mathrm{El}$ símil aristotélico de la casa evidencia que entre lo artificial y lo natural existe una «identidad de mecanismo», esto es, un proceso único para la actualización de las substancias, pues, aunque hubiera sido de forma artificial o natural, ésta se habría generado de igual manera. Así, se refleja la existencia de un único proceso de generación - el natural - que, como en el ejemplo de la casa, ${ }^{14}$ concluye según lo dictado por el orden natural.

El artefacto, en consecuencia, adquiere un estatuto ontológicamente defectivo respecto a lo natural — dado que solo constituye un reflejo o un complemento de lo que es por naturaleza-, cuyo origen se halla en la posesión de un principio de creación diferente para lo natural y para lo artificial. Según Aristóteles, mientras que la naturaleza «[...] tiene en sí misma un principio de movimiento y de reposo», ${ }^{15}$ lo artificial necesita recurrir a algo exterior a sí, pues los objetos artificiales «[...] no tienen en sí mismas ninguna tendencia natural al cambio». ${ }^{16}$ De esta forma, el artefacto, en palabras de Hernández Reynés, «[...] carece de una forma que pueda ser causa de otro individuo como él. Esta carencia es tan importante que es por lo que se hace necesaria la intervención de una causa formal que no coincide con la que se encuentra en acto en la cosa misma y que en cierto modo le es ajena». ${ }^{17}$ Así pues, será precisamente la falta de una causa formal propia lo que obligue al artefacto a acudir a una causa ajena a él que le permita actualizarse, de modo que «[...] los productos técnicos no sean propiamente substancias o que si lo son lo sean devaluadas».. ${ }^{18}$

Las consecuencias de la comprensión aristotélica de lo artefactual apuntan a una imposibilidad para modificar la naturaleza, en tanto que ésta posee un orden que la técnica no puede alterar debido a su carácter defectivo, unido a la tesis peripatética de que la naturaleza hace las cosas del mejor modo posible apoyándose en la causalidad final. Así, el papel de los artefactos queda supeditado al de la naturaleza, dado que la técnica sólo desarrolla su actividad

12 W.K.C. Guthrie, 2005, p.120

13 «[... for Aristotle, nature is the original or model and art is derivative» (H.S. Lang, 1998, p.46).

14 «Por ejemplo, si una casa hubiese sido generada por la naturaleza, habría sido generada tal como lo está ahora por el arte. Y si las cosas por naturaleza fuesen generadas no sólo por la naturaleza sino también por el arte, serían generadas tales como lo están ahora por la naturaleza» Aristóteles, Física, II, 8 (199 a 10-15).

15 Aristóteles, Física, II, 1 (192 b 10).

16 Ibid., 1 (192 b 15).

17 Hernández Reynés, 2009, p. 297.

18 Ibid., p.297. 
como complemento o reflejo de la naturaleza, impidiéndose una alteración por medio de la técnica que actúe más allá de lo natural.

Descartes se rebelará contra esta forma de concebir la técnica, pues él encarna a un sujeto activo que busca la transformación en la naturaleza para ponerla al servicio del hombre, y es precisamente lo artefactual aquello que permite al individuo intervenir en ésta. La caracterización que Aristóteles atribuye tanto a lo natural como a lo artificial $-\mathrm{y}$ la relación establecida entre ambos- será aquello que Descartes rechace. El sujeto activo cartesiano atenta contra la concepción aristotélica de lo artificial, pues ésta impide alcanzar el objetivo último de la ciencia cartesiana -el dominio de la naturaleza con vistas a obtener frutos. Se pueden señalar dos elementos aristotélicos como fuente de impedimentos para la consecución de los objetivos cartesianos de la ciencia: (a) la comprensión del artefacto como ontológicamente defectiva; (b) la tesis de que la naturaleza hace las cosas de la mejor forma posible. Descartes no puede asumir estas dos tesis, que se complementan la una a la otra, porque, respecto a (a), ello limita el papel posible de la técnica al condenarla a ofrecer resultados inferiores a los de la naturaleza. Asimismo, si aquello que la naturaleza nos otorga es lo mejor que es posible obtener, entonces el papel de la técnica sólo puede reducirse al de imitar o alcanzar aquello que naturalmente se da, puesto que ésta no podría aspirar a obtener algo mejor que lo que la naturaleza nos ofrece. Por tanto, estas dos tesis, al establecer lo natural como culminación y minusvalorar el poder de la técnica, anulan la capacidad de intervención en la naturaleza, siendo necesaria su supresión para la consecución de un sujeto activo.

En primer lugar, Descartes manifiesta en la Dióptrica de diversas formas su renuncia a (b). La concepción cartesiana de lo natural —encarnada en los llamados «órganos naturales»— niega la tesis aristotélica en dos sentidos al sostener que la naturaleza es defectuosa ${ }^{19}$ y que ésta es susceptible de ser perfeccionada. Aristóteles ya había explorado en su Sobre la generación de los animales $^{20}$ la posibilidad de fallos en la naturaleza ocasionados por la «casualidad» (autómaton), ${ }^{21}$ no obstante, la defectividad a la que alude Des-

19 El propio Descartes utilizará a lo largo de toda la Dióptrica el término «defecto» (defauts) para referirse a los errores con los que la naturaleza nos ha constituido: «Por tanto, para que podamos remedir en virtud del arte estos defectos» (Descartes, Dióptrica, AT, VI, p.150).

20 Cf. Aristóteles, Sobre la generación de los animales, IV, caps.3-4.

21 Aristóteles desarrolla en el segundo libro de su Física una distinción entre «casualidad» y «suerte», siendo la casualidad responsable del error surgido en la naturaleza, pues «cuando se genera algo contrario a la naturaleza no decimos que se ha generado fortuitamente, sino por casualidad» (Aristóteles, Física, II, 197b30-35). La casualidad será aquello que impida a la naturaleza actualizarse según su causa final, siendo la responsable de errores en la naturaleza como la existencia de «monstruos»: «[...] the production of monstrous births $[\ldots]$ though they 
cartes se diferencia de la aristotélica en que no refiere a un error concreto de la naturaleza causado por accidente, sino a un defecto general constitutivo en todos los sujetos:

Y si bien la Naturaleza no nos ha concedido la posibilidad de observarlos a una distancia menor de uno o de medio pie, sin embargo, con el fin de suplir mediante el arte cuanto es posible. ${ }^{22}$

Ello permitirá, en consecuencia, que se pueda determinar como defectiva a la naturaleza misma, pues la causa del defecto no se hallará, como en Aristóteles, en algo al margen de ésta, sino por la forma en que ésta nos ha constituido. El rechazo de (b), por otra parte, no impedirá a Descartes indicar qué condiciones determinan la obtención una visión perfecta, tal y como hace en el Discurso Séptimo de la Dióptrica, ${ }^{23}$ lo cual implicará asumir que existen formas posibles de determinar la vista perfecta al margen de los mecanismos naturales, es decir, que aquello que la naturaleza nos otorga - los órganos naturales - deja de representar el modelo ideal al que deben aspirar los órganos artificiales.

Por tanto, el rechazo a la tesis (b) se efectuará conforme a tres críticas: (1) la naturaleza nos otorga facultades defectuosas —en el sentido de que poseen defectos generales de base; (2) es posible mejorar lo naturalmente dado; (3) es posible determinar las condiciones perfectas de la visión suprimiendo el papel de la naturaleza, que para Aristóteles conformaba el canon de lo que debía ser. ${ }^{24}$ Será precisamente el abandono de (b) lo que posibilite una reevaluación de (a), aboliendo el carácter defectivo atribuido a la tecnología y asignándole, en su lugar, una función transformadora de la naturaleza. De ese modo, aunque Descartes afirme que la medicina pueda ser una forma de corregir los órganos naturales, serán los «órganos artificiales» aquello que verdaderamente contribuya a suprimir los defectos que hay en lo natural, pues los inventos descritos a lo largo de toda la Dióptrica constituyen las formas de mejorar dichos defectos de la naturaleza.

En conclusión, la concepción cartesiana de lo artificial y llo natural niega las dos tesis aristotélicas, propiciando una comprensión en la que los artefactos representan la forma en la que el sujeto puede intervenir en la naturaleza para provecho de los hombres.

are not «according to nature» since the form supplied by the male parent has failed to master the matter contributed by the female. Such productions are fortuitous» (D. Ross, 1974, p.76).

22 Descartes, Dióptrica, AT, VI, p.154

23 Cf. Ibid., pp.148-9.

24 El repudio a la causalidad final se vincula a la supresión del papel de canon que ejercía la naturaleza. Para un análisis del rechazo cartesiano a las causas finales: Cf. Jaume, 2012, pp.477-91. 


\section{LA REDEFINICIÓN CARTESIANA DE LOS LÍMITES DE LO NATURAL Y LO ARTIFICIAL EN LA DIÓPTRICA}

Una vez evidenciado el rechazo cartesiano a la concepción aristotélica de lo artefactual, trataré de elucidar qué tipo de relación establece Descartes, en consecuencia, entre lo natural y lo artificial apelando para ello al vínculo existente entre los «órganos naturales» y los «órganos artificiales» como paralelismo.

Como Rossi ha indicado, uno de los rasgos principales de la ciencia moderna, a la que Descartes contribuye, es «La afirmación de una substancial no-diversidad entre los productos del arte y los de la naturaleza» ${ }^{25}$ que posibilita la reevaluación cartesiana de lo artefactual por la que los órganos artificiales pierden su carácter defectivo y asumen un mismo estatus ontológico. Para Descartes «[...] no hay diferencia ninguna entre las máquinas que construyen los artesanos y los cuerpos que la naturaleza por sí misma ha formado», ${ }^{26}$ reflejando una equiparación ontológica que se encarna en una concepción mecanicista del mundo donde todo es igualmente reducible a materia. Será precisamente la equiparación artificial-natural aquello que permita perfeccionar los órganos naturales sin que sea atacado el carácter ontológico de los órganos artificiales:

Por tanto, para que podamos remediar por medio del arte estos defectos. ${ }^{27}$

Ahora bien, este papel por el que lo artificial perfecciona lo natural parecería en principio preservar la tesis aristotélica de que lo natural determina lo que deben ser las cosas. Así, a pesar de que lo natural pueda en algunos aspectos poseer defectos, ello nos indicaría hacia donde debe tender lo artificial para poder «completar» el órgano natural. Con todo, aunque intérpretes como Guenancia ${ }^{28}$ y determinados fragmentos parezcan dar cuenta de que Descartes respalda esta línea, el carácter perfeccionador de lo artificial debe leerse en otro sentido, apelando a las consecuencias extraídas de los órganos naturales. Para Descartes, un órgano artificial debe por lo general intentar mejorar un órgano natural para reducir sus defectos, no obstante, puede suceder el caso en que un órgano artificial sustituya a un órgano natural:

25 P. Rossi, 1965, p.131.

26 Descartes, Principios de la filosofía, AT, IX, p.321.

27 Descartes, Dióptrica, AT, VI, p.150.

28 Guenancia señala una línea interpretativa similar a la del presente artículo, con todo, su tesis apela a que «La finalité naturelle n'est pas niée, elle est plutôt subordonnée a l'usage ou à l'utilité de la vie humaine» (P. Guenancia, 2010, p.352), y, en consecuencia, lo artificial no logra independizarse de lo natural, sino que su relación con ello continúa ejerciéndose en términos meramente complementarios: «D'abord parce que l'art humain agrandit la mécanique imperceptible de la Nature» (Ibid., p.355). 
Finalmente, cuando nos dispongamos a emplazar un cristal ante los ojos, deberemos imitar en cuanto sea posible a la Naturaleza en todo aquello que conocemos que ha observado al formarlos y no deberemos perder ninguna de las ventajas que nos ha concedido si no es para obtener otra mayor. ${ }^{29}$

Se puede hallar un ejemplo de ello en alguno de los órganos artificiales que Descartes diseña en el Discurso Séptimo de la Dióptrica (AT, VI, p.156 y sig.), donde propone la construcción de un artefacto consistente en un tubo de vidrio colmado de agua - tratando de ejemplificar un proceso de refracción para así perfeccionar nuestra visión- que, con el fin de ampliar las imágenes de los objetos accesibles e inaccesibles que recibimos, sustituiría un órgano natural como es la pupila:

[...] la verdadera pupila sería no solamente inútil sino también perjudicial en este caso, pues excluiría por su reducido tamaño los rayos que podrían dirigirse hacia los lados del fondo del ojo, impidiendo de este modo que las imágenes se extendiesen sobre el mismo espacio que podrían hacerlo si la pupila no fuese $\tan$ estrecha. ${ }^{30}$

[...] cuando nos servimos de estas lentes de las que acabamos de hablar, anulamos toda la utilidad que posee la pupila puesto que es el orificio que hemos practicado, el que viene a hacer las veces de pupila y el que permite el acceso de la luz que proviene del exterior. ${ }^{31}$

Así pues, la forma en que Descartes relaciona artificial y natural no apela a un patrón fundado en lo natural, pues el criterio por el que debemos, por regla general, mejorar y no sustituir los órganos naturales es que ellos nos reportan usualmente consecuencias útiles. No se trata entonces de que, siguiendo la tesis aristotélica, lo natural encarne un modelo de cómo deben ser las cosas. El criterio alternativo mediante el que se relacionarán los órganos artificiales y naturales será la utilidad de que nos provean, dado que, en la línea de Guenancia, «La perspectiva del uso y la utilidad es entonces el sustituto de la finalidad $\gg,{ }^{32}$ que era determinada por lo natural. El criterio de la utilidad se constituirá sobre las condiciones de la visión perfecta detalladas por Descartes, pues, partiendo de que «[...] las invenciones que puedan contribuir a dilatar [el] poder [de la vista] han de ser las más útiles ${ }^{33}$ para dirigir la conducta de nuestra vida, cuanto más se aproxime un órgano a satisfacer dichas condicio-

29 Descartes, Dióptrica, AT, VI, p.152.

30 Ibid., p.157.

31 Ibid., p.160.

32 Mi traducción, P. Guenancia, 2010, p.351.

33 Descartes, Dióptrica, AT, VI, p.81. 
nes, más útil será. En consecuencia, se establecerá una clasificación gradual de los órganos naturales y artificiales según permitan aproximarse en mayor o menor medida a la condición concreta de la visión perfecta, de manera que se hallarán, por un lado, órganos naturales más defectuosos ${ }^{34}$ que otros $\mathrm{y}$, por otro lado, órganos artificiales mejores ${ }^{35}$ que otros.

Será esta gradación lo que justifique el que, en unos casos, los órganos artificiales complementen a los órganos naturales para suprimir el defecto y, en otros casos, los sustituyan. Ordinariamente, los órganos naturales nos ofrecen una determinada utilidad en tanto que satisfacen de forma relativamente completa las condiciones para la visión perfecta. Por ejemplo, con vistas a satisfacer la tercera condición, consistente en que «[...] los rayos [de luz] [...] deben ser suficientemente intensos como para mover los pequeños filamentos del nervio óptico, pudiendo así sentir; ahora bien, su intensidad no debe ser tal que impida la visión», ${ }^{36}$ la Naturaleza nos ha otorgado la capacidad de estrechar o agrandar nuestras pupilas. Ahora bien, cuando los órganos artificiales nos concedan una utilidad tal que la mejora del órgano natural no sea equiparable,

34 Por ejemplo, respecto a la condición (1), el defecto consistirá en que las imágenes que obtengamos a través de los rayos no sean distintas. Tal y como señala Descartes, nosotros ya estamos constituidos con un defecto de base que nos impide «[...] curvar en modo tal la superficie de nuestros ojos como para permitirnos ver con precisión los objetos muy próximos, a distancia como de uno o medio dedo» (Descartes, Dióptrica, AT, VI, p.112). De esta forma, nuestros ojos poseen el defecto de que, a una distancia de uno o medio dedo, no nos permiten obtener una imagen distinta del objeto, no obstante, podemos percibir los objetos accesibles de forma cercana y lejana. Este defecto podrá ser agravado cuando la naturaleza nos otorgue unos ojos con los que, además de ese defecto, nos impida ver de lejos o de cerca: «[...] en otros casos aún ha errado más, pues ha dado a algunos unos ojos de tal forma que no les sirven sino para mirar los objetos alejados [...] en otros casos, ha permitido la formación de ojos que no sirven sino para observar cosas próximas» (Ibíd., p.112) De esta forma, el defecto en los ojos será mayor conforme impida en mayor medida la captación distinta de imágenes, esto es, distanciándose más de la vista perfecta.

35 Descartes establece una gradación en la Dióptrica mostrando que hay órganos artificiales mejores que otros. La evaluación de la utilidad de los órganos artificiales se desarrollará conforme a dos criterios: (1) comodidad en el uso y en la fabricación; (2) si suple de mejor forma los defectos del órgano natural: «[...] que prestemos atención a dos condiciones con vistas a seleccionar los más adecuados de acuerdo con nuestra finalidad. En virtud de la primera condición debemos seleccionar aquéllos cuyas figuras sean más simples y más cómodamente trazables y tallables. En virtud de la segunda deben seleccionarse aquéllos por cuyo medio los rayos que provienen de otros puntos del objeto , tales como E-E, penetren en el ojo poco más o menos como si proviniesen de otros puntos, tales como F-F [Es decir, que remedien el defecto]» (Descartes, Dióptrica, AT, VI, pp. 151-2).

36 Descartes, Dióptrica, AT, VI, p.149. 
pues hay defectos en los órganos naturales donde «[...] [la Naturaleza] aún ha errado más», ${ }^{37}$ se podrá efectuar una sustitución.

Esta forma de vincular artificial y natural conllevará, en consecuencia, el que los artefactos adquieran una autonomía respecto a lo natural, plasmándose en la sustitución del símil organicista aristotélico por el símil mecanicista cartesiano. ${ }^{38}$ En el momento en que el órgano artificial es capaz de reemplazar al órgano natural, queda evidenciado que lo artificial puede actuar al margen de lo natural. Así, lo artificial no representa ya para Descartes un complemento de algo natural, sino la forma genuina en la que el sujeto puede influir en la naturaleza más allá del modelo expresado en lo natural. La consecuencia extraíble acontecerá en forma de sujeto activo que interviene en lo natural para obtener las consecuencias mejores sobre el criterio de la utilidad. Descartes invertirá en cierta forma el orden aristotélico, pues la defectividad será trasladada a lo natural, mientras que lo artificial acogerá una autonomía que le posibilite aspirar a lo mejor — siguiendo el criterio de tratar de obtener aquello que nos otorgue más ventajas.

Por tanto, mediante el desarrollo de estos órganos artificiales, el sujeto podrá adquirir un conocimiento más profundo del mundo. El microscopio propuesto por Descartes permitiría, por ejemplo, «[...] observar diversas mezclas y disposiciones de pequeñas partes de la que están compuestos los animales y plantas [...] obteniendo de tal observación una gran ventaja para nuestro conocimiento de la naturaleza». ${ }^{39} \mathrm{Si}$ mediante $«[. .$.$] los principios de la filosofía$ de Aristóteles [...] no ha cabido realizar progreso alguno por medio de ellos después de haber sido respetados durante siglosı ${ }^{40}$ es debido a que el progreso requiere de intervención en la naturaleza, cosa que determinadas tesis aristotélicas impiden. Así, la importancia del conocimiento de la naturaleza resultado del uso de los instrumentos será fundamental en tanto que será aquello que nos permita hacernos dueños y poseedores de la naturaleza a través de la intervención en ella, con los consiguientes frutos que implican para la mejora de la vida. De manera que esta relectura del papel de lo artificial y lo natural será fundamental, pues será el germen que posibilite la intervención del sujeto en forma de artefacto.

37 Ibid., p.150.

38 Para un análisis de las implicaciones de dicha sustitución y del papel del símil de la máquina en el proyecto filosófico cartesiano: Cf. Vaccari, 2008, pp.287-336.

39 Descartes, Dióptrica, AT, VI, p. 226.

40 Descartes, Principios de la filosofia, AT, VIII, pp.18-19 


\section{CONCLUSIÓN}

La crítica cartesiana a las tesis aristotélicas conlleva, como se ha puesto de manifiesto, la redefinición de lo artificial en unos términos que desvinculan e independizan lo artificial de lo natural, posibilitando así la existencia de un sujeto activo capaz de intervenir en la naturaleza mediante la mejora o sustitución de nuestros órganos naturales en base a un criterio de utilidad. Los artefactos conforman para Descartes la manera en que podemos perfeccionar nuestras herramientas epistémicas independientemente del patrón natural, aspirando a un conocimiento que ambiciona algo más que la contemplación, el conocimiento es conocimiento para algo, concretamente, la intervención en la naturaleza hacia la obtención de frutos.

Bajo dicha comprensión activa del conocimiento, la ciencia adquirirá un papel fundamental, siendo necesaria la existencia de un corpus teórico sobre cómo es el mundo como paso previo a la manufactura de los mejores artefactos ${ }^{41}$ que intervengan en él. En otras palabras, tal y como ejemplifica la Dióptrica, la construcción de artefactos que intervengan en la visión requiere previamente de una teoría científica sobre la luz (definición de la luz, ley de refracción,...) y una teoría sobre el funcionamiento anatómico de los órganos perceptivos, ya que la modificación de la naturaleza exige el conocimiento de la forma en que ésta funciona para averiguar dónde falla y cómo mejorarla:

Así mismo considero que la ejecución de cuanto exponga [para la construcción de las lentes] debe depender de la habilidad de los artesanos, que generalmente carecen de estudios. Por esta razón intentaré hacerme inteligible a todo el mundo y no omitir no suponer nada que deba ser enseñado por otras ciencias [para la construcción de las lentes]. Esta es la razón por la que comenzaré refiriéndome a la explicación de la luz y de sus rayos; a continuación, habiendo realizado una breve descripción de las partes del ojo, detallaré la forma en que se realiza la visión. ${ }^{42}$

El carácter instrumental de dicha ciencia surgirá, entonces, de la finalidad a la que es encaminada la ciencia: el dominio de la naturaleza a través de artefactos construidos por la ciencia. La manufacturación de artefactos, resultado de la ciencia, se dirige a un doble propósito: (1) adquirir «[...] un conocimiento

41 La construcción de artefactos no exige de por sí un conocimiento científico profundo, tal y como evidencia el caso criticado por Descartes al comienzo de la Dióptrica respecto a la fabricación de lentes por Santiago Metio. Ahora bien, la manufacturación de los mejores artefactos posibles —donde se enmarcan las mejores lentes posibles - sí exigirá una serie de conocimientos teóricos previos. Éste será el motivo por el que la Dióptrica exponga durante los seis primeros capítulos su concepción científica de fenómenos vinculados a la construcción de lentes.

42 Descartes, Dióptrica, AT, VI, p.82-3. 
de la Naturaleza mucho más vasto y perfecto», ${ }^{43}$ es decir, ampliar y perfeccionar nuestro conocimiento del mundo mediante el uso de artefactos como el telescopio; (2) mejorar nuestra vida mediante la obtención de los frutos del árbol de la ciencia: medicina, moral y mecánica. De esta forma se evidencia que los artefactos permiten obtener los frutos de la intervención en la naturaleza y a su vez mejorar las herramientas de la investigación científica para así alcanzar más y mejores frutos.

En suma, la ciencia cartesiana no puede entenderse como un corpus de conocimiento guiado por la idea aristotélica del conocimiento por sí mismo. La propuesta cartesiana reproducida en la Dióptrica pone de manifiesto que los intereses científicos de Descartes apuntan a un conocimiento para algo, la ciencia surge para la obtención de resultados, no como una pura contemplación. El rechazo de Descartes hacia las tesis aristotélicas posibilita dicha dimensión instrumental y, en definitiva, la existencia de un sujeto activo.

\section{REFERENCIAS BIBLIOGRÁFICAS}

ARISTÓTELES, (1995): Fisica, trad. G. de Echandía, Madrid: Gredos

CLARKE, D., (1982): Descartes' philosophy of science, Manchester University Press

DAINVILLE, F., (1954): «L'enseignement des mathématiques dans les collèges jésuites de France du XVI au XVIII siècles», Revue d'histoire des Sciences et de leurs applications, Vol. 7, pp.6-21 y 109-123

DESCARTES, R.: Oeuvres de Descartes, Vols. I-XII, Adam \& Tannery (Ed.), Paris: Leopold Cerf, 1897-1913

DESCARTES, R. (2011): Descartes, trad. Flórez Miguel, Madrid: Gredos

DESCARTES, R. (1981): Discurso del método, Dióptrica, Meteoros y Geometría, trad. Quintás Alonso, Madrid: Alfaguara

GARBER, D., (1992): Descartes' metaphysical physics, Chicago: University of Chicago Press

GUENANCIA, P., (2010): Lire Descartes, París: Gallimard

GUTHRIE, W.K.C., (2005): Historia de la filosofía griega VI, trad. Medina González, Barcelona: RBA

HERNÁNDEZ REYNÉS, (2009): «Lo natural y lo artificial en Aristóteles y Francis Bacon. Bases para la tecnología moderna», Ontology Studies, 9, pp. 297

JAUME, A., (2012): «De explicaciones por inferencia a la mejor explicación a explicaciones basadas en mecanismos. Una reflexión en torno a los proyectos epistemológicos de Aristóteles y Descartes y sus consecuencias», Angelicum, Vol. 89, No.2, pp.477-92

43 Ibíd., p.81. 
LANG, H.S., (1998): The Order of Nature in Aristotle's Physics: Place and the elements, Cambridge: Cambridge University Press.

MUMFORD, L., (1979): Técnica y civilización, trad. Aznar de Acevedo, Madrid: Alianza Ed.

RIBE, N., (1997): «Cartesian Optics and the Mastery of Nature», Isis, 88: pp.42-61.

ROSS, D., (1974): Aristotle, London: Methuen.

ROSSI, P., (1965): Los filósofos y las máquinas 1400-1700, trad. Carreras, Barcelona: Labor

SMITH, A. M., (1987): «Descartes's Theory of Light and Refraction. A Discourse on Method», Transactions of the American Philosophical Society, Vol. 77, No.3, pp.1-92

VACCARI, A., (2008): «Legitimating the Machine: The Epistemological Foundation of Technological Metaphor in the Natural Philosophy of René Descartes», en C. Zittel (Ed.), Philosophies of Technology. Francis Bacon and his Contemporaries, 2008, Leiden, pp.287-336

WILliAMS, B., (1978): Descartes: The Project of Pure Inquiry, Harmondsworth: Penguin

WOLF-DEVINE, C., (1993): Descartes on seeing: Epistemology and Visual Perception, Southern Illinois University Press

YATES, F., (1983): Giordano Bruno y la tradición hermética, trad. Domenec Bergara, Barcelona: Ariel

Sergio García Rodríguez es doctorando en la Universitat de les Illes Balears.

Lineas de investigación: Epistemología. y Pragmatismo.

Publicaciones:

(2015): «Los conceptos de «hecho»y «consecuencias útiles» en la crítica russelliana a la teoría de la verdad pragmatista de William James», Estudios Filosóficos, Vol. LXIV, No. 186, pp. 299-322.

(2016): «Justificación y error en Descartes: un argumento pragmatista en la validación cartesiana del criterio de claridad y distinción», Revista de filosofía, Vol. 41, No1, pp.97-109.

Correo electrónico: sergio.garcia@uib.es 